Editorial

\title{
Between Evidence and Emotions: Emotional Appeals in Science Communication
}

\author{
Monika Taddicken * and Anne Reif \\ Department of Communication and Media Sciences, Technische Universität Braunschweig, 38106 Braunschweig, Germany; \\ E-Mails: m.taddicken@tu-braunschweig.de (M.T.), a.reif@tu-braunschweig.de (A.R.) \\ * Corresponding author
}

Submitted: 19 February 2020 | Published: 18 March 2020

\begin{abstract}
In the field of science communication, there is currently a great deal of discussion on how individuals can be reached, not only through fact-oriented communication, but also through emotional appeals and 'edutainment' approaches. This discussion has been further intensified by the changing conditions of new media environments. From an academic viewpoint, the discussion is often met with scepticism. However, categorical statements about a supposed dichotomy of emotion and rationality are misleading. What is needed are differentiated arguments and analyses. Nevertheless, emotions in science communication are an often overseen research field. With this thematic issue, we seek to enrich the scientific discourse by providing research from authors coming from different perspectives using different concepts, methods, and cases. In this editorial, we summarise the contribution of ten different articles on three levels: (1) emotions of science communicators, (2) emotional(ised) content, and (3) emotions of science communication audiences.
\end{abstract}

\section{Keywords}

audiences; communicators; content; emotions; entertainment; rationality; science communication

\section{Issue}

This editorial is part of the issue "Emotions and Emotional Appeals in Science Communication" edited by Monika Taddicken (Technische Universität Braunschweig, Germany) and Anne Reif (Technische Universität Braunschweig, Germany).

(C) 2020 by the authors; licensee Cogitatio (Lisbon, Portugal). This article is licensed under a Creative Commons Attribution 4.0 International License (CC BY).

\section{The Relevance of Studying Emotions in Science Communication}

In 1985, the Royal Society of London declared that a better public understanding of science (about results as well as methods) is necessary for individual citizens to make reasoned, personal decisions in most aspects of daily life (Royal Society of London, 1985). Scientists, scientific institutions, and the media were asked to encourage this public understanding of science by communicating more information to the public. Empirical research, however, could not prove a positive correlation between the amount of information and knowledge of science the public has and its positive attitude towards scientific topics. As a result, the assumption of a knowledge deficit that can be addressed through better information distribution has been criticised. It was said that the narrow emphasis of the deficit approach does not recognise that knowledge is only one factor among many influences that are likely to guide how individuals reach judgments (Bubela et al., 2009; Sturgis \& Allum, 2004).

This has led to a general shift in focus towards a new 'public engagement' or interactive model that emphasises deliberative contexts, the relevance of participation (Bubela et al., 2009), and emotions in the communication process. In particular, new media environments, in the form of digital communication and social media, create a low-threshold participation opportunity with the potential to encourage citizens' participation in science (Stilgoe, Lock, \& Wilsdon, 2014). Many innovative public engagement formats have been developed, such as science slams, hackday formats or science cafés, which have the potential to not only enhance audiences' scientific knowledge but also arouse positive emotions. So far, 
entertainment has been acknowledged as important for science communication perceptions and effects in particular (Nisbet \& Goidel, 2007). An 'edutainment' approach focusing on the emotional experience of the audience has been indicated (Gerber, 2011) in the emerged 'experimental field' of practical science communication.

From an academic viewpoint, emotionalised science communication is often regarded as trivial and met with scepticism. However, little empirical research has been carried out relating to usage, reception, and the effect of these new formats. There are scarcely any scientific findings concerning participation, as well as the motivation for and the emotional appeal of it. The academic debate stays on normative grounds (Fähnrich, 2017; Stilgoe et al., 2014), and in particular the relevance of emotions has been neglected this far-although urgently needed more than ever.

Public discussions around so-called 'alternative facts' and 'fake news' direct further towards the negative aspects of emotional appeals and debate. Seen as contrary to the Habermasian ideal of public communication, the discourse on social media is not only positively discussed-it is attributed to trolls and bots, potential echo chambers and paradoxes of participation (Schmidt, 2018), which also influences (somehow) the public discourse on topics such as science. Social media are called 'emotion media' because of their basic functional logic of communication (Eisenegger, 2017). Against the backdrop of 'hate speech' in social media and the allegedly linked verbal coarsening in the debating culture, so-called 'sensitivity communication' (in German, Befindlichkeitkskommunikation; Barth \& Wagner, 2016) is commonly seen in negative light. Here, emotions are often explicitly associated with an overarching trend of disaffection with elites and (possibly) a loss of trust in societal authorities and systems, particularly against the background of leading politicians who publicly question the truth of scientific results and thus contest fundamental epistemological criteria.

However, what is the role of emotions in the scientific discourse? Does an 'absolute dichotomy of ratio and emotion' (Neverla, 2017) even exist? Clearly, the relationship between affective and cognitive engagement with issues needs to be rethought and reinterpreted. For communication on scientific topics in particular-that are characterised by a high degree of complexity and uncertainty-it is necessary to question the extent to which evidence and emotion can actually be understood as opposites. Emotions may affect communication as well as reasoning processes, but may also promote social and moral behaviour. Thus, categorical statements on emotions and rationality would be considered misleading (Pham, 2007), which is why this thematic issue helps to close the research gap about emotions in the relationship between science and the public.

In sum, we identified three reasons and perspectives why it seems more important than ever to bring research on emotion, in the context of science com- munication, into focus: (a) practical science communication and (b) scientists and researchers debate the necessity and potential effects of new science communication paradigms. Furthermore, the relevance also derives from (c) recent developments of the public debate connected to the use of online media and phenomena, such as disinformation and so-called 'fake news.'

This essay will introduce different research perspectives regarding emotions and emotional appeals in science communication, and summarise the contribution of the articles published in this thematic issue. Different concepts of emotions exist, which can be researched and discussed in various contexts and from different angles. This diversity is reflected by the articles of this thematic issue.

\section{Different Perspectives of Emotions and Emotional Appeals in Science Communication}

The starting point of the idea for this thematic issue was the annual conference of the Science Communication Division of the German Communication Association (DGPuK), in February 2019 in Braunschweig, Germany. Many of the authors presented their research projects at the conference before writing their articles. The conference welcomed more than 70 participants coming from different disciplines and perspectives, including practical science communicators. We then called on the international scientific community.

Accordingly, the articles of this thematic issue reflect the scientific discourse on emotions and emotional appeals in science communication from diverse angles. Different emotions and emotional aspects are studied with various methodological and disciplinary approaches using several science communication formats or science topics as examples. Furthermore, we consider the diversity of concepts and definitions of emotions that can be found in the academic discourse. Thus, the readers will find variations across the articles. We are convinced that the multidisciplinary and multiperspective view of this issue has the potential to enrich the scientific discourse.

Following a common structure of communication research, we will differentiate between three levels in which emotions are relevant in the science communication process: (1) the communicators; (2) the content; and (3) the audience. This differentiation helps to structure the articles published in this thematic issue (see Figure 1).

\subsection{Emotions of Science Communicators}

There is a tension between emotion and rationality in science, which results from the methodological principle of 'objectivity.' Science should be individual-independent, but, naturally, scientists themselves are confronted with emotions during the research process-as well as science communicators (including science communicating scientists) during the communication process. In his 


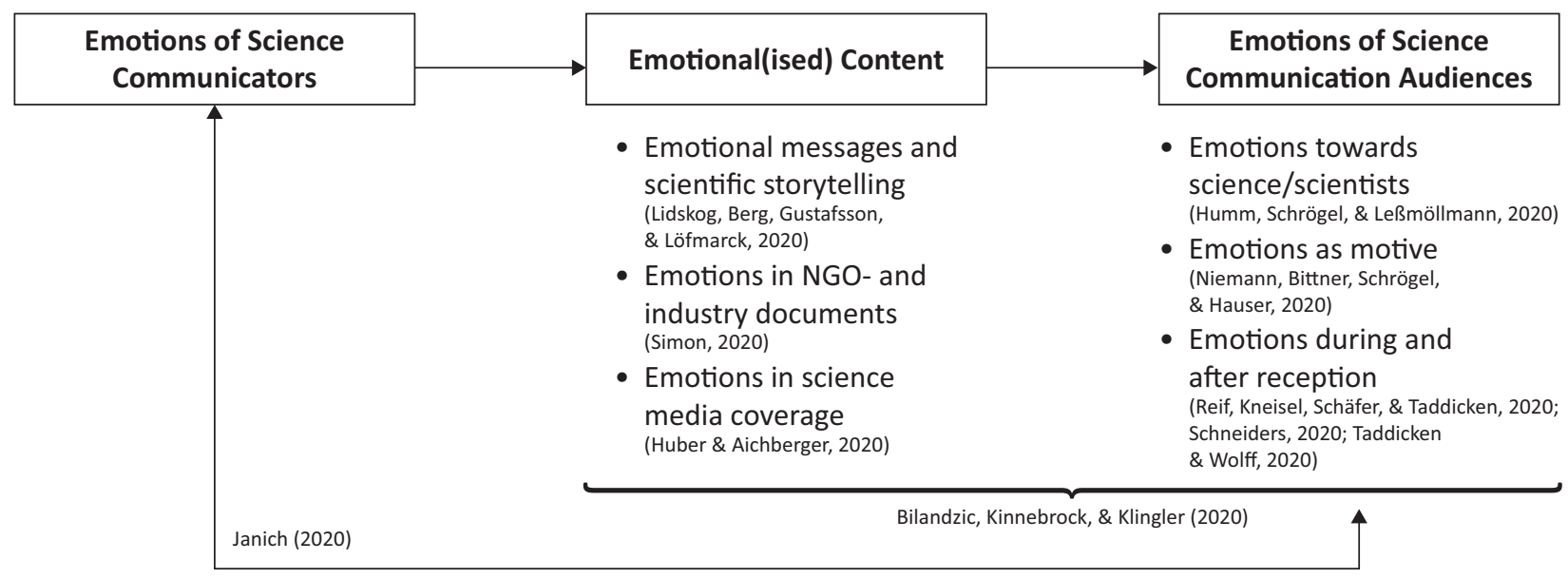

Figure 1. Overview of articles in this issue.

conference keynote in Braunschweig, Rainer Bromme (University of Münster) recommended scientists to show their emotions and to make them reflexively a topic. He argued that emotions are indicators of social values: What feels good is valuable and worth striving for (see also Pham, 2007). In addition, because individuals know that their emotions are strongly correlated with their values, they assume this is also the case with other people (Bromme \& Gierth, in press).

However, other studies find cues that emotional language can harm the trustworthiness of scientists as well as the credibility of their arguments (König \& Jucks, 2019a, 2019b). This is somehow confirmed by the first article in this thematic issue by Janich (2020) and by Humm, Schrögel, and Leßmöllmann (2020), who focus more strongly on the audience perspective (see Section 2.3). Humm et al. (2020) and Janich (2020) indicate that science communication audiences, as well as audiences excluded by science communication in general, expect scientific experts to be objective and to objectively report on scientific issues. However, both articles argue that science that does not permit emotions seems culturally distant or even contradictory to the emotional(ised) daily lives that audiences experience. Having these stereotypes of science and scientists in mind, one asks what happens if scientific experts are not objective but openly express emotional reactions in the public discourse? Analysing the comments in science blogs, Janich (2020, p. 116) observes in the first article that:

When the experts become impatient or respond with irony, and when they do not (want to) live up to these expectations due to a lack of empathy or due to, at best, egocentric empathy, the interaction quickly becomes emotionally charged.

In the centre of this article are emotions expressed in the textual dialogue between scientific experts and the public. From her linguistic research perspective on the dialogue between science and the public in a new media environment, the author calls for more reciprocal empathy.

\subsection{Emotional(ised) Content}

It is often asked how science and scientific results should be presented to 'successfully' reach a wider public (usually without clarifying what 'successful' means). With regard to emotions: Can or should the rational position of science and the presentation of abstract results be abandoned in favour of more emotional narratives? Or, does this approach undermine the neutrality and thereby the credibility of science? So far, there has been little research on the level of emotionality within science communication, and whether or not science communication varies when it comes to different times, communicators or formats. The second thematic area of this thematic issue aims to discuss questions about professional emotional science communication content. Three articles in this thematic issue analyse texts by different science communicators on the topics of climate change (Lidskog, Berg, Gustafsson, \& Löfmarck, 2020), possible risks of neonicotinoid pesticides (Simon, 2020) and-related-honey bee colony losses (Huber \& Aichberger, 2020).

By comparing two different storylines as a case study (dystopic story vs. optimistic story) about environmental and climatic change, Lidskog et al. (2020) show that scientific storytelling does not only present 'cold facts' and provide normative orientation, but it also reflects emotional appeals such as fear or hope. The combination of both is assumed to facilitate climate friendly actions. Emotions in this article refer to the process to produce (scientists' perspective) and receive (audiences' perspective) knowledge, and are understood as an instrument to facilitate actions.

Similar results are revealed by Simon's (2020) linguistic analysis of different knowledge claims of possible risks of neonicotinoid pesticides, which are published in documents by the agricultural industry compared to environmental organisations. The author approaches emotions from a rhetorical perspective by distinguishing between ethos (measured as trustworthiness: expertise, integrity, and benevolence) and pathos. Ethos and pathos 
are both reflected by the texts but different rhetoric patterns are detected. While texts by the agricultural industry strongly focus on demonstrating their scientific ethos, environmental organisations highlight concerns about the use of neonicotinoid pesticides.

As most people receive their information about science from media content, examining emotions in the media coverage about science and scientific issues is of high relevance. Huber and Aichberger (2020) refer to this perspective with a quantitative content analysis-a commonly used method in communication research. They find that media coverage about honey bee colony losses in Austrian newspapers not only refers to scientific expertise, but is highly emotionalised-especially in tabloid papers. Emotionalisation is expressed more frequently through the use of rhetorical devices than by explicit references to negative or positive emotions.

\subsection{Emotions of Science Communication Audiences}

Bearing in mind that, within a public discourse, scientific facts are understood and interpreted individually, it becomes significant to look closely at the recipients' perspective. The question is how (emotional) content is emotionally processed by the audience.

In the fifth article, Bilandzic, Kinnebrock, and Klingler (2020) present a theoretical model that combines the emotional content and its emotional processing and effects on users' emotions by focusing on emotional potentials of science stories. The authors include a theoretical classification of different patterns in science narratives, as well as a typology of emotions (discrete and complex) that can be evoked by different narratives.

One of the prime issues of practitioners is: (1) why science communication often reaches highly educated and science-literate audiences; and (2) how underserved audiences can be reached and engaged. To help answer these questions, Humm et al. (2020) investigate the reasons why underserved audiences feel excluded by science communication. They use a qualitative approach by conducting (group) interviews with different minorities in Germany and refer to negative emotions such as fear of being left out, as well as negative self-perception and emotional barriers. Besides material exclusion factors, the authors highlight how underserved audiences sense an emotional distance to science.

In contrast, Niemann, Bittner, Schrögel, and Hauser (2020) study the audiences and their motivations to attend the innovative science communication format of science slams that combine scientific content and entertainment. Applying a mixed-methods approach, entertainment is understood here as hedonic emotion that motivates individuals to attend science slams. Although people's primary motive to attend a science slam is the need to be entertained, through the use of eyetracking methodology the authors reveal that the audience focuses longer on the scientific aspects than the entertaining elements of the presentations. Thus, the data indicate a good compatibility of scientific content and entertainment.

One different science communication format that emphasises users' (emotional) engagement is the online explainer video. Reif, Kneisel, Schäfer, and Taddicken (2020) highlight the importance of YouTube videos and sciencetubers as science communicators, as well as the necessity to examine viewers' emotional assessment of scientific experts for the evaluation of their trustworthiness. Thus, emotions are understood in connection to trustworthiness and refer to three types of emotional assessment of scientific experts. While the findings of the experimental online survey also suggests that scientific experts who appear in a TV interview setting are perceived as more competent and regarded as typical scientists, sciencetubers are evaluated as entertaining and explaining comprehensibly.

Online environments comprise very heterogeneous contents communicated by different agents; many are non-compliant, dissonant, but also false information can be found online (Pfetsch, Löblich, \& Eilders, 2018). With that in mind, Taddicken and Wolff (2020) examine how people react to online 'fake news' about climate change and how they try to resolve the cognitive dissonance evoked. Using mixed-methods, the article provides insight into the individual affective arousal and coping strategies after being confronted with opinionchallenging disinformation. If dissonance can be dissolved, individuals feel relieved and satisfied. Otherwise they state dissatisfaction and frustration.

Building on the idea of feelings of cognitive dissonance in connection with information processing, Schneiders (2020) presents results of an experimental study. He demonstrates that feelings of cognitive dissonance do not affect people's recall of information. Against the bad reputation of explainer videos, the results indicate that videos and the so-called 'scrollytelling' are most effective, whereas text is most efficient regarding the recall of information.

\section{Conclusion}

This issue offers numerous opportunities for further thoughts, research, and discussions. We believe that the multidisciplinary and multiperspective view in this thematic issue, which also takes practical aspects into account, allows a more comprehensive examination of emotions in the supposedly rational field of science and science communication.

Apparently, this issue provides some answers regarding emotionalised communication content as well as answering the question about how the audience is affected, particularly regarding the manifold different science communication formats, but also within the new media environments. However, the variety of different theoretical concepts and perspectives on emotions reflected in this issue underlines the difficulty of giving a simple answer to the question where science communi- 
cation is to be located between evidence and emotions.

What is striking is the small number of contributions in the area of 'emotions of science communicators.' This research gap should be filled in the future. It includes the questions of emotions in scientific processes, next to the science communication processes, and, with this, of the underlying values and norms of scientists. In the field of science of science communication, it is often asked how science can best be communicated and what makes science communication effective. Here, emotions are understood as a functional means of disseminating knowledge and an instrumental perspective is applied. Beyond that, however, research can focus more on the relationship of science and the public. Emotional processes in science communication should be investigated more closely in the future-not only at the micro, but also at the meso and macro levels of society. The mutual processes should be investigated, i.e., the emotional effects on scientists and science communicators. In this issue, concepts like sympathy, empathy, and ethos/pathos were identified as relevant. However, research has to acknowledge that nowadays many more stakeholders than just science and the public (thus, the audience) come into play, such as political stakeholders, NGOswith their own goals and strategies, but also with their own emotions and values.

\section{Acknowledgments}

We would like to acknowledge the work of many reviewers who contributed to this issue and of the authors who allowed us to be part of their writing process. Many thanks to the journal and its friendly and patient staff. We would also like to thank Birte Fähnrich and Jutta Milde (Speakers), Susann Kohout, Francine Meyer, Nina Wicke, Katharina Willems, and Laura Wolff, as well as all involved students for their contributions to organising the annual conference of the Science Communication Division of the German Communication Association (DGPuK) at the Technische Universität Braunschweig, Germany, in February 2019. The conference contributions were helpful for many authors of articles published in this issue. One of these authors is Ingrid Aichberger, who has passed away in October 2019. In honour and remembrance, we would like to devote this thematic issue to her. As a dedicated researcher in the field of science communication, she will be sadly missed by the scientific community.

\section{Conflict of Interests}

The authors declare no conflicts of interest.

\section{References}

Barth, N., \& Wagner, E. (2016). Erhitzte Öffentlichkeitzur medialen Transformation öffentlicher Kommunikation auf Facebook [The heated public-About the media transformation of public communication on Facebook]. POP-ZEITSCHRIFT. Retrieved from http://www.pop-zeitschrift.de/2016/03/05/socialmedia-maerzvon-niklas-barth-und-elke-wagner5-32016

Bilandzic, H., Kinnebrock, S., \& Klingler, M. (2020). The emotional effects of science narratives: A theoretical framework. Media and Communication, 8(1), 151-163. https://doi.org/10.17645/mac.v8i1.2602

Bromme, R., \& Gierth, L. (in press). Rationality and the public understanding of science. In M. Knauff \& W. Spohn (Eds.), The handbook of rationality. Cambridge, MA: MIT Press.

Bubela, T., Nisbet, M. C., Borchelt, R., Brunger, F., Critchley, C., Einsiedel, E., . . . Caulfield, T. (2009). Science communication reconsidered. Nature Biotechnology, 27(6), 514-518. https://doi.org/10.1038/nbt0609514

Eisenegger, M. (2017). Vorwort: Digitaler Strukturwandel der Öffentlichkeit-Professionelle Informationsmedien nötiger denn je! [Editorial: Digital structural change of the public-Professional information media more necessary than ever!] In fög-Forschungsinstitut Öffentlichkeit und Gesellschaft/UZH (Eds.), Qualität der Medien. Schweiz - Suisse - Svizzera. Jahrbuch 2017 [Quality of media. Switzerland. Yearbook 2017] (pp. 7-16). Basel: Schwabe. https://doi.org/10.5167/uzh147243

Fähnrich, B. (2017). Wissenschaftsevents zwischen Popularisierung, Engagement und Partizipation [Science events between popularisation, engagement, and participation]. In H. Bonfadelli, B. Fähnrich, C. Lüthje, J. Milde, M. Rhomberg, \& M. S. Schäfer (Eds.), Forschungsfeld Wissenschaftskommunikation [Science communication as a field of research] (pp. 165-182). Wiesbaden: Springer Fachmedien Wiesbaden. https://doi.org/10.1007/978-3-658-128982_9

Gerber, A. (2011). Trendstudie Wissenschaftskommunikation-Vorhang auf für Phase 5: Chancen, Risiken und Forderungen für die nächste Entwicklungsstufe der Wissenschaftskommunikation (Vol. 1) [Science communication trend study-Raise the curtain for the 5th stage: Chances, risks, and demands for the next stage of developments in science communication]. Berlin: Edition innovare/innokomm Forschungszentrum.

Huber, B., \& Aichberger, I. (2020). Emotionalization in the media coverage of honey bee colony losses. Media and Communication, 8(1), 141-150. https://doi.org/ 10.17645/mac.v8i1.2498

Humm, C., Schrögel, P., \& Leßmöllmann, A. (2020). Feeling left out: Underserved audiences in science communication. Media and Communication, 8(1), 164-176. https://doi.org/10.17645/mac.v8i1.2480

Janich, N. (2020). What do you expect? Linguistic reflections on empathy in science communication. Media 
and Communication, 8(1), 107-117. https://doi.org/ $10.17645 / \mathrm{mac} . v 8 \mathrm{i} 1.2481$

König, L., \& Jucks, R. (2019a). Hot topics in science communication: Aggressive language decreases trustworthiness and credibility in scientific debates. Public Understanding of Science, 28(4), 401-416. https://doi. org/10.1177/0963662519833903

König, L., \& Jucks, R. (2019b). Influence of enthusiastic language on the credibility of health information and the trustworthiness of science communicators: Insights from a between-subject web-based experiment. Interactive Journal of Medical Research, 8(3), e13619. https://doi.org/10.2196/13619

Lidskog, R., Berg, M., Gustafsson, K. M., \& Löfmarck, E. (2020). Cold science meets hot weather: Environmental threats, emotional messages and scientific storytelling. Media and Communication, 8(1), 118-128. https://doi.org/10.17645/mac.v8i1.2432

Neverla, I. (2017). Öffentlichkeit im Emotionsmodus: Wendezeiten im wissenschaftlichen und journalistischen Diskurs [The public in emotion mode: Turning point in the scientific and journalistic discourse]. Hamburg: University of Hamburg. Retrieved from https://www.wiso.uni-hamburg.de/fachbereichsowi/professuren/lilienthal/bilder/abstractssymposium-mediendemokratie-2017.pdf

Niemann, P., Bittner, L., Schrögel, P., \& Hauser, C. (2020). Science slams as edutainment: A reception study. Media and Communication, 8(1), 177-190. https:// doi.org/10.17645/mac.v8i1.2459

Nisbet, M. C., \& Goidel, R. K. (2007). Understanding citizen perceptions of science controversy: Bridging the ethnographic-survey research divide. Public Understanding of Science, 16(4), 421-440. https://doi.org/ 10.1177/0963662506065558

Pfetsch, B., Löblich, M., \& Eilders, C. (2018). Dissonante Öffentlichkeiten als Perspektive kommunikationswissenschaftlicher Theoriebildung [Dissonant public spheres as perspective for theory development in communication research]. Publizis- tik, 63(4), 477-495. https://doi.org/10.1007/s11616018-0441-1

Pham, M. T. (2007). Emotion and rationality: A critical review and interpretation of empirical evidence. $R e$ view of General Psychology, 11(2), 155-178. https:// doi.org/10.1037/1089-2680.11.2.155

Reif, A., Kneisel, T., Schäfer, M., \& Taddicken, M. (2020). Why is a scientific expert perceived as trustworthy? Emotional assessment within TV and YouTube videos. Media and Communication, 8(1), 191-205. https:// doi.org/10.17645/mac.v8i1.2536

Royal Society of London. (1985). The public understanding of science. London: The Royal Society of London. https://royalsociety.org/topics-policy/publications/ 1985/public-understanding-science

Schmidt, J.-H. (2018). Social Media: Medienwissen kompakt [Social media: Compact media knowledge]. Wiesbaden: Springer VS. https://doi.org/10.1007/ 978-3-658-19455-0

Schneiders, P. (2020). What remains in mind? Effectiveness and efficiency of explainers at conveying information. Media and Communication, 8(1), 218-231. https://doi.org/10.17645/mac.v8i1.2507

Simon, N. (2020). Investigating ethos and pathos in scientific truth claims in public discourse. Media and Communication, 8(1), 129-140. https://doi.org/10. 17645/mac.v8i1.2444

Stilgoe, J., Lock, S. J., \& Wilsdon, J. (2014). Why should we promote public engagement with science? Public Understanding of Science, 23(1), 4-15. https://doi.org/ 10.1177/0963662513518154

Sturgis, P., \& Allum, N. (2004). Science in society: Reevaluating the deficit model of public attitudes. Public Understanding of Science, 13(1), 55-74. https:// doi.org/10.1177/0963662504042690

Taddicken, M., \& Wolff, L. (2020). 'Fake news' in science communication: Emotions and strategies of coping with dissonance online. Media and Communication, 8(1), 206-217. https://doi.org/10.17645/mac. v8i1.2495

\section{About the Authors}

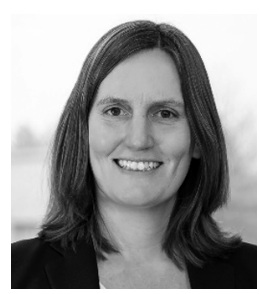

Monika Taddicken is a Professor of Communication and Media Sciences at the Technische Universität Braunschweig, Germany. She received her PhD in Communication Research from the University of Hohenheim, Germany, and is currently working on the audience's perspective of science communication. She has also published several articles on computer-mediated communication and social media, as well as on survey methodology.

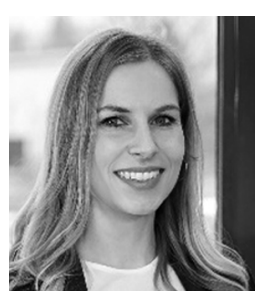

Anne Reif is a Research Assistant at the Department of Communication and Media Sciences at the Technische Universität Braunschweig, Germany. She holds an MA degree in Media and Communication Science from the Ilmenau University of Technology, Germany. She is currently working on her PhD project about trust in science and the use of online media from the audience's perspective. Her further research interests are in the field of gender studies. 